\title{
USE OF CERES-WHEAT MODEL FOR WHEAT YIELD FORECAST IN BEIJING
}

Xian Wang ${ }^{1,2}$, Chunjiang Zhao ${ }^{2, *}$, Cunjun $\mathrm{Li}^{2}$, Liangyun Liu ${ }^{2}$, Wenjiang Huang $^{2}$, Pengxin Wang ${ }^{1}$

${ }^{1}$ China agricultural University, Beijing, P. R. China 100083

${ }^{2}$ National Engineering Research Center for Information Technology in Agriculture, Beijing, P. R. China 100097

* Corresponding author, Address: National Engineering Research Center for Information Technology in Agriculture, Beijing 100097, P. R. China, Tel: +86-10-51503411, Email: zhaocj@nercita.org.cn

Abstract: The CERES-Wheat model was applied to simulate yields from 2005 to 2007 at Xiaotangshan of northern Beijing. Experiment datum required by CERESWheat model were all collected and checked. In addition, 1974-2004 climate records were taken and calculated as predictive weather scenario used for yield forecasting. The model calibration adopted simulation results of 2005 and which of the other two years were used for validation. Model calibration was made through comparing the field-observed and model-simulated results at five stages: (i) dates of anthesis and maturity; (ii) values of LAI; (iii) biomass yields of anthesis and maturity; (iv) dry matter of leaf, stem, and grain; (v) final wheat yield. This study revealed that CERES-Wheat model can be used for the prediction of wheat growth and yield in Beijing.

Keywords: crop simulation model, wheat, yield forecast

\section{INTRODUCTION}

China has turned to be the largest producer of wheat in the world (FAO 2004), and nearly $95 \%$ of which is winter wheat. Considering the importance of wheat for the economy, government policy and food requirements of the state, there is a need for reliable estimates of wheat production under varied environments. On the basis of early-warning information of successive yield

Please use the following format when citing this chapter:

Wang, X., Zhao, C., Li, C., Liu, L., Huang, W. and Wang, P., 2009, in IFIP International Federation for Information Processing, Volume 293, Computer and Computing Technologies in Agriculture II, Volume 1, eds. D. Li, Z. Chunjiang, (Boston: Springer), pp. 29-37. 
predictions during the growing season, producers and marketing boards could, for example: adjust use of fertilizers and herbicides, revise marketing plans, and decide on options for following seasons.

The official estimates of crop production in China are based on three methods at present. The first is statistical method, which works through complete enumeration for crop acreage and sample crop cutting experiments for yield. Crop sampling leads to large labor force-, material resources- and money-consuming; the second way calculates crop yield through weather model, which can get a accurate result but with a disadvantage that short of acreage information; the last method is using remote sensing (RS) to estimate grain outputs.

Crop simulation model is a process based model (de Wit, 1982), which simulates crop growth and development combine with changing climate stages and varied environmental conditions. In many cases, quantitative information on production can only be obtained through crop simulation studies and long-term climatic records (MacDonald and Hall, 1980; Bouman et al., 1995). Providing accurate estimates of the benefits and risks of alternative crop management systems with expected yield before final harvest has placed an increasing demand on crop simulation models. The use of crop simulation models for predicting crop yield has been studied extensively and there has been an increased interest in association with spatial variability and precision farming (Hoogenboom, 2000; Sadler et al., 2000; Paz et al., 2001; M. Bannayan et al., 2004). As a further extension of this approach, the predicted results can be used to determine certain management decisions.

The objective of this study was to evaluate the application of the dynamic crop process model CERES (crop estimation through resource and environment synthesis)-Wheat for forecasting final grain yield for winter wheat under growing conditions in Beijing.

\section{MATERIALS AND METHODS}

\subsection{Experiment data}

\section{Site description}

Winter wheat ('Jingdong 12') was sown during the autumn of 2004/2005, 2005/2006 and 2006/2007 at Xiaotangshan, which located in Changping of

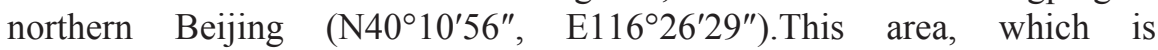
representative of the irrigated fields of Beijing, is characterized by a semi- 
arid climate. At this place, winter wheat is the major crop sowed by farms, and the mean air temperature yearly is $12.6^{\circ} \mathrm{C}$.

\section{Data description}

The CERES-Wheat model uses daily weather data, together with a set of parameters describing crop, soil and management factors, to simulate wheat growth over the growing season (Hunt et al., 2001). To use the model in Beijing, it was necessary to obtain local values of the above parameters. Experimental information, including latitude, longitude, sowing date, descriptions of the soil series, the number of collected samples, and climate information (Table 1) are all collected from2004 to 2007.

Table 1. Distribution of precipitation

\begin{tabular}{|c|c|c|c|c|c|c|c|c|c|c|c|c|c|}
\hline \multirow{2}{*}{$\begin{array}{l}\text { Season } \\
\text { Month }\end{array}$} & \multicolumn{3}{|c|}{ Spring } & \multicolumn{3}{|c|}{ Summer } & \multicolumn{3}{|c|}{ Autumn } & \multicolumn{3}{|c|}{ Winter } & \multirow[t]{2}{*}{ Total } \\
\hline & 3 & 4 & 5 & 6 & 7 & 8 & 9 & 10 & 11 & 12 & 1 & 2 & \\
\hline Rain(mm) & 9.7 & 16.6 & 26.8 & 87.9 & 194.1 & 181.4 & 48.8 & 24.6 & 5.6 & 1.3 & 2.7 & 4.9 & 584.2 \\
\hline rain/season & & 53.1 & & & 443.4 & & & 78.8 & & & 8.9 & & 584.2 \\
\hline$\%$ & & $9.1 \%$ & & & $75.9 \%$ & & & $13.5 \%$ & & & $1.5 \%$ & & $100 \%$ \\
\hline
\end{tabular}

Standard meteorological data with the exception of solar radiation was obtained using DAVIS station from 2004 to 2007. This station provided daily values of the maximum and minimum air temperature $\left({ }^{\circ} \mathrm{C}\right)$, rainfall $(\mathrm{mm})$ and total wind run $(\mathrm{m} / \mathrm{s})$. Sunshine hours were gained from China Meteorological data Sharing Service System, and they were converted to daily total radiation $\left(\mathrm{MJ} / \mathrm{m}^{2}\right)$ using the method of dumin Weng (1997). Besides those, 30 years (1975-2006) of daily weather data (maximum and minimum air temperature, ${ }^{\circ} \mathrm{C}$; rainfall, $\mathrm{mm}$; sunshine hours, $\mathrm{hr}$ ) were taken from China Meteorological data Sharing Service System as an input for yield forecasting. Soil inputs include drainage and runoff coefficients, first-stage evaporation and soil albedo, water-holding characteristics for each individual soil layer, and rooting preference coefficients at several depth increments. The model also requires saturated soil water content and initial soil water content for the first day of simulation. The description of the soil characteristics were shown as Figure 1 (Xuzhang Xue et al., 2003). The brown soils have characteristically light textures with water holding capacities to a depth of $1 \mathrm{~m}$ of $150 \mathrm{~mm}$ or less, so the sampling of the soil deep to $1 \mathrm{~m}$ and separated into 6 layers. The crop management data were obtained from field experiments, including plant population, planting depth, and date of planting. If the crop is irrigated, the date of application and amount is also required.

\subsection{CERES-wheat model}

Current major crop model systems include DSSAT (Decision Support System for Agrotechnology Transfer; USA, Canada), SUCROS (Netherland) and 
APSIM (Australia) etc. CERES-Wheat model, as a process-oriented crop model provides some benefits over purely empirical models, is one of the main models that have been incorporated in DSSAT (Hoogenboom et al., 1994). The study works with CERES-Wheat Model through DSSAT 4.
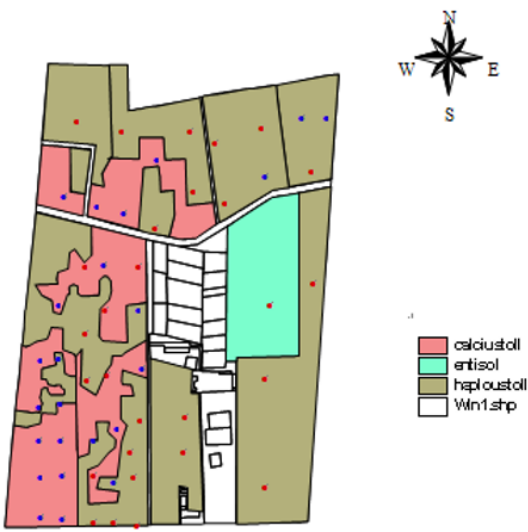

Figure 1. The soil characteristics of Xiaotangshan

CERES-Wheat is a dynamic crop simulation model that was originally developed under the auspices of the USDA-ARS Wheat Yield Project and the U.S. government multiagency AGRISTARS program (Ritchie and Otter, 1985). It forms the basis of IBSNAT, the International Benchmark Sites Network for Agrotechnology Transfer (Uehara, 1985), can be used to simulate the growth and yield of wheat under different environments. The model has been tested successfully with data from around the world. Output results could be biomass accumulation and partitioning, leaf area index (LAI), water and $\mathrm{N}$ balance, crop growth and yield based on daily time steps etc (Godwin and Singh, 1998; Ritchie et al., 1998).

\subsection{Cultivar calibration}

In order to evaluate the applicability of the CERES-Wheat model to Beijing, calibration of the model was required. The key process of model calibration was adjusting six variety-specific genetic parameters of Jingdong12. Three of these are related to developmental aspects and the others related to the growth of the crop. P1V and P1D define the sensitivity of a variety to vernalization and photoperiod. The third developmental parameter, P5, is the grain-filling duration coefficient. G1, G2 and G3 are the kernel number coefficient, kernel weight coefficient and spike number coefficient, respectively (S. S. HUNDAL, 1997). When the predicted values of the relevant growth and yield were compared with the observed values, 
the six genetic coefficients were increased or decreased from the initial values. After an iterative process, those values of the coefficients which most realistically simulated the growth and yield of wheat were selected.

Model calibration was made by comparing the field-observed and modelsimulated results of five stages: (i) dates of anthesis and maturity; (ii) values of LAI (leaf area index); (iii) biomass yields of anthesis and maturity; (iv) dry matter of leaf, stem, and grain; (v) final wheat yield. The CERES-Wheat model was calibrated to simulate the growth and development of winter wheat using the field-observed crop data of the 2004/2005 season experiment. The comparison of model-simulated and field-observed data was gained for validation at the period 2005/2006 and 2006/2007. In addition, 30 years (1975-2006) historical weather information was taken as statistical weather result to predict yield.

\section{RESULTS AND DISCUSSION}

The CERES-Wheat model simulated from realistic weather conditions, crop genotypes, soil properties and crop management practices got simulated-results. The values derived from statistic weather data (19752006), which used as input variables of model, were called predicted-values. This method is one of the main methods to predict weather and has been used and practiced widely. All inputs except weather data were prescribed as discussed in the previous sections. The experiment conducted during the 2004/2005 growing seasons was used to calibrate the model, and the experiment conducted during the 2005/2006 and 2006/2007 growing seasons were used for model evaluation. Forecasts of wheat yield were generated for the period 2006/2007.

Overall, the field-observed and model-simulated anthesis dates and maturity dates were in close agreement (Table 2). The difference of simulated and actual dates of anthesis is less than 6 days, which of the autumn is less than 5 days.

Table 2. Comparison of observed and simulated anthesis and physiological maturity dates of winter wheat for different crop years

\begin{tabular}{|c|c|c|c|c|c|c|c|}
\hline \multirow{2}{*}{$\begin{array}{l}\text { Crop } \\
\text { year }\end{array}$} & \multirow{2}{*}{$\begin{array}{l}\text { Sowing } \\
\text { date }\end{array}$} & \multicolumn{2}{|c|}{$\begin{array}{c}\text { Anthesis date } \\
\text { (Days after sowing) }\end{array}$} & \multirow{2}{*}{$\begin{array}{c}\text { Deviation } \\
\text { (No. of days) }\end{array}$} & \multicolumn{2}{|c|}{$\begin{array}{l}\text { Physiological maturity date } \\
\text { (Days after sowing) }\end{array}$} & \multirow{2}{*}{$\begin{array}{l}\text { Deviation } \\
\text { (No. of days) }\end{array}$} \\
\hline & & Observed & simulated & & Observed & simulated & \\
\hline $2004 / 05$ & $27 / 9 / 2004$ & 223 & 225 & 2 & 262 & 263 & 1 \\
\hline $2005 / 06$ & $28 / 9 / 2005$ & 229 & 233 & 6 & 265 & 269 & 4 \\
\hline $2006 / 07$ & $27 / 9 / 2006$ & 226 & 232 & 6 & 263 & 264 & 5 \\
\hline
\end{tabular}

Experiment data of 2006/2007 season was taken as an example for evaluation. Comparison of simulated-values, observed-values and predicted- 
values (2006/2007) of LAI was shown as Figure2.LAI simulated by the model corresponded reasonably well with that actually observed in the field, although simulated values shows a little higher at the last 35 days. Similarly, predicted wheat LAI has also shown negative trends in the period of subsequent period. While predicted values delayed much from that of actual, especially at the period of end Anthesis and maturity. The maturity date of forecasted is 270, 6 days later than simulated date. The reason may be attributed to uncertain weather conditions in the region.

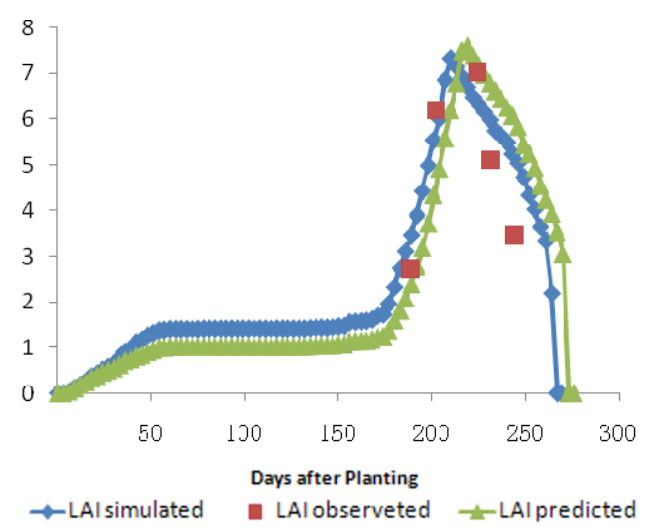

Figure 2. Comparison of simulated-values, observed-values and predicted-values of LAI for 2006

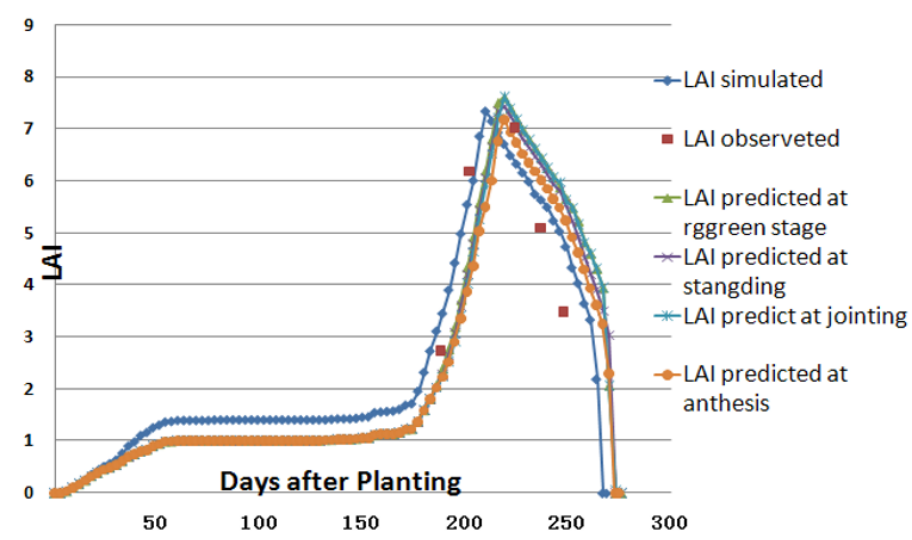

Figure3. Comparison of simulated-values,observed-values and predicted-values at main stages of LAI for 2006

Simulated wheat yield $(7525 \mathrm{~kg} / \mathrm{ha})$ and predicted yield $(7736 \mathrm{~kg} / \mathrm{ha})$ was much higher than the actual wheat yields $(6992 \mathrm{~kg} / \mathrm{ha})$. The deviation may be on account of dissatisfactory environment conditions, for instance water stress, $\mathrm{N}$ deficiency or unbalance of nutrient at subsequent period. The 
statistical weather condition has a serious disadvantage that it averaged rainfall values to every day, the total water gross was the same, but it likely make a day-by-day irrigation to wheat. That is one of the reasons predicted yield much higher than simulated wheat yield.

We also worked on crop growth forecasting from main growth stage: rggreen stage, standing, jointing and anthesis. The certain growth stage as a dividing line, before that time measured weather data was used and after that time statistic weather condition used as input data. LAI at rggreen stage, standing and jointing was close to each other; while LAI result at anthesis showed obvious improve. At this experiment region, the influence of real weather data to predict result between rggreen stage and anthesis is tiny. There are 40 days between anthesis and maturity, at this period the more real meteorological data used the precision the result is. In practice, policy makers could predict wheat yield at rggreen stage got a general forecasting yield and got a more exact result at subsequent period forcasting.

\section{SUMMARY AND CONCLUSIONS}

As wheat is a staple crop in China, pre-harvest forecast of wheat yield is necessary to allow policy makers in the government to design policies for export/import, price fixing, storage and transportation. Crop simulation models are process based and consider almost all factors affecting the crop growth and development. With their obvious advantages, crop simulation models have become a favorite tool for yield forecasting.

The crop simulation model was run on recommended levels of inputs for the fields, but simulated and predicted yields are high. This could be due to following reasons: (a) farmers are not following the appropriate recommendation; (b) around $1-5 \%$ of the standing crop is lost during various agronomical practices such as fertilizer applications, pesticide applications, herbicide applications, tillage, irrigation etc. (A. S. NAIN, 2004); (c) $8-10 \%$ of the crop yield in fields is damaged during threshing and transportation; (d) some loss also occurs due to pests. Some assumptions made in the CERESWheat model may not be realistic in certain situations and these could be addressed in future investigations.

Though the approach released in the present study for wheat yield estimation and prediction showed reasonably good accuracy, it can be further improved by considering issues such as: (a) affects of plant diseases and insect pests; (b) spatial variability in soil properties; (c) spatial variability of weather; (d) interaction between rotated crops. Future research for yield forecasting can carry through by adopting the use of GIS (geographic information system) and RS (remote sensing). 
The present study demonstrates the ability of the CERES-Wheat model to provide regular pre-harvest forecasting of wheat yields in Beijing. Although there is diversity, the total variety trend was corresponded reasonably well with that actually value. The model can act as a useful tool for Winter Wheat yield forecast in Beijing.

\section{ACKNOWLEDGEMENTS}

This work was subsidized by the National High Tech R\&D Program of China (2006AA10Z201, 2006AA10Z203), National Natural Science Foundation of China (40701120, 40701119), Beijing excellent talent training (20071D0200500046).

\section{REFERENCES}

A. S. NAIN1, V. K. DADHWAL, T. P. SINGH. 2004. Use of CERES-Wheat model for wheat yield forecast in central Indo-Gangetic Plains of India. Journal of Agricultural Science. 142: 59-70.

A.C. Chipanshi, E.A. Ripley, R.G. Lawford. 1997. Early prediction of spring wheat yields in Saskatchewan from current and historical weather data using the CERES-Wheat model. Agricultural and Forest Meteorology. 84 : 223-232.

Bouman, B.A.M., C.A. van Diepen, P. Vosen, T.van Der Wal. 1995. Application of systems approaches at the farm and regional levels. Simulation and system analysis tools for crop yield forecasting.325-340.

C. W. Fraisse, K. A. Sudduth, N. R. Kitchen. Calibration of the CERES-MAIZE model for simulation site-specific crop development and yield on claypan soils. Applied Engineering in Agriculture. 17(4): 547-556

DE WIT, C. T. Simulation of living systems. 1982. In Simulation of Plant Growth and Crop Production, Simulation Monographs. 1-24.

E. John Sadler, Philip J. Bauer, Warren J. Busscher et al. 2000. Site-specific analysis of a droughted corn crop: II. Water use and stress. Agronomy Journal.

Hoogenboom, G., J.W. Jones, P.W. Wilkens, W.D.Batchelor, et al. 1994. Crop models. 95244.

Hoogenboom,G. 2000. Contribution of agrometeorology to the simulation of crop production and its applications. Agric. For. Meteorol. 103: 137-157.

Hunt, L.A., J.W.White, G.Hoogenboom. 2001. Agronomic data: Advances in documentation and protocols for exchange and use. Agric. Syst. 70:477-492.

JiangMin, Jin Zhiqing, Ge Daokuo, Shi Chun. Validation and modification of CERESWHEAT model in winter wheat production region of China. Journal of JiangSu agricultural college.64-67.

JT Ritchie, S Otter. 1985. Description and performance of CERES-Wheat: a user-oriented wheat yield model. Crop husbandry. 159-175. 
M. Bannayan, N. M. J. Crout, Gerrit Hoogenboom. 2004. Application of the CERES-Wheat Model for Within-Season Prediction of Winter Wheat Yield in the United Kingdom. MODELING.

Ma Yuping, Wang Shili, Wang Futang. 2005.A Prelim Inary Study On the Application of Crop Simulation models In Agrometeorological Services. Journal of applied meteorological science.293-303

MacDonald, R.B., F.G.Hall.1980. Global crop forecasting. Science. 208-670.

Ritchie, J.T., U.Singh, D.C.Godwin et al. 1998. Cereal growth, development and yield. 79-97.

Royce, F.S., J.W. Jones, J.W.Hansen.2001. Model-based optimization of crop management for climate forecast applications. Trans.ASAE 44:1319-1327.

S. S. HUNDAL, PRABHJYOT-KAUR. 1997. Application of the ceres \pm Wheat model to yield predictions in the irrigated plains of the Indian Punjab. Journal of Agricultural Science, Cambridge. 129:13-18.

Uehara, G. 1985. The International Benchmark Sites Network for Agrotechnology Transfer (IBSNAT). Wheat Growth and Modelling. Proceedings of a NATO Advanced Research Workshop. 271-274.

XIE Wenxia,YAN Lijiao,WANG Guanghuo. 2006. Simulation and Validation of Rice Potential rowth Process in Zhejiang by Utilizing WOFOST Model. Chinese Rice Sci. 20(3):319 32.

Xuzhang Xue, Larry C Munn. 2003. Soil Survey Results in Xiaotangshan Station. 